OPEN ACCESS

Edited by:

Consuelo Borras,

University of Valencia, Spain

Reviewed by:

Cristina Mas Bargues,

University of Valencia, Spain

Juan Gambini,

University of Valencia, Spain

${ }^{*}$ Correspondence:

Nesrin Kartal Ozer

nkozer@marmara.edu.tr

Specialty section:

This article was submitted to

Aging, Metabolism and Redox Biology,

a section of the journal

Frontiers in Aging

Received: 07 October 2021

Accepted: 14 December 2021

Published: 20 January 2022

Citation:

Demirel-Yalciner T, Sozen E and Ozer NK (2022) Endoplasmic Reticulum Stress and miRNA Impairment in Aging and Age-

Related Diseases.

Front. Aging 2:790702.

doi: 10.3389/fragi.2021.790702

\section{Endoplasmic Reticulum Stress and miRNA Impairment in Aging and Age-Related Diseases}

\author{
Tugce Demirel-Yalciner ${ }^{1}$, Erdi Sozen ${ }^{1,2}$ and Nesrin Kartal Ozer ${ }^{1 *}$ \\ ${ }^{1}$ Department of Biochemistry, Faculty of Medicine, Marmara University, Maltepe, Turkey, ${ }^{2}$ Genetic and Metabolic Diseases \\ Research and Investigation Center (GEMHAM), Marmara University, Maltepe, Turkey
}

Aging is a physiological process defined by decreased cellular and tissue functions. Reduced capacity of protein degradation is one of the important hallmarks of aging that may lead to misfolded protein accumulation and progressive loss of function in organ systems. Recognition of unfolded/misfolded protein aggregates via endoplasmic reticulum (ER) stress sensors activates an adaptive mechanism, the unfolded protein response (UPR). The initial step of UPR is defined by chaperone enhancement, ribosomal translation suppression, and misfolded protein degradation, while prolonged ER stress triggers apoptosis. MicroRNAs (miRNAs) are non-coding RNAs affecting various signaling pathways through degradation or translational inhibition of targeted mRNAs. Therefore, UPR and miRNA impairment in aging and age-related diseases is implicated in various studies. This review will highlight the recent insights in ER stress-miRNAs alterations during aging and age-related diseases, including metabolic, cardiovascular, and neurodegenerative diseases and several cancers.

Keywords: aging, endoplasmic reticulum stress, microRNA, metabolic disorders, neurodegenerative diseases, cardiovascular diseases, cancer

\section{INTRODUCTION}

Aging is a process that results in decreased body homeostasis and increased risk of disease or death (Ito and Barnes, 2009). Mainly, nine hallmarks in aging have been described as follows: 1) telomere attrition, 2) epigenetic alterations, 3) genomic instability, 4) mitochondrial dysfunction, 5) deregulated nutrient sensing, 6) cellular senescence, 7) stem cell exhaustion, 8) altered intercellular communication, and 9) loss of proteostasis (Lopez-Otin et al., 2013). In recent years, metabolic disorders, including obesity, cardiovascular diseases (CVDs), and neurodegenerative disorders, have also been described as other hallmarks in the aging process (Spinelli et al., 2020).

Abbreviations: APP, amyloid $\beta$-precursor protein; ASK1, apoptosis signal-regulating kinase; ATF6, activating transcription factor 6; ATF4, activating transcription factor 4; CHOP, C/EBP homologous protein; CVD, cardiovascular disease; eIF2 $\alpha$, eukaryotic initiation factor 2a; FOXO1, forkhead box protein O 1; GADD34, growth arrest and DNA damage-inducible 34; GRP78, glucose-regulated protein 78; GRP94, glucose-regulated protein 94; IRE1, inositol-requiring enzyme; IRS1, insulinreceptor substrate; JNK, c-Jun amino-terminal kinase; NAFLD, nonalcoholic fatty liver disease; PDI, protein disulfide isomerase; PDIA6, protein disulfide isomerase family A member 6; PI3K, phosphoinositide-3-kinase regulatory subunit 1; PERK, protein kinase-like ER kinase; RIDD, regulated IRE1-dependent decay; TRAF2, tumor necrosis factor receptorassociated factor 2; UPR, unfolded protein response; XBP1, X-box binding protein 1. 


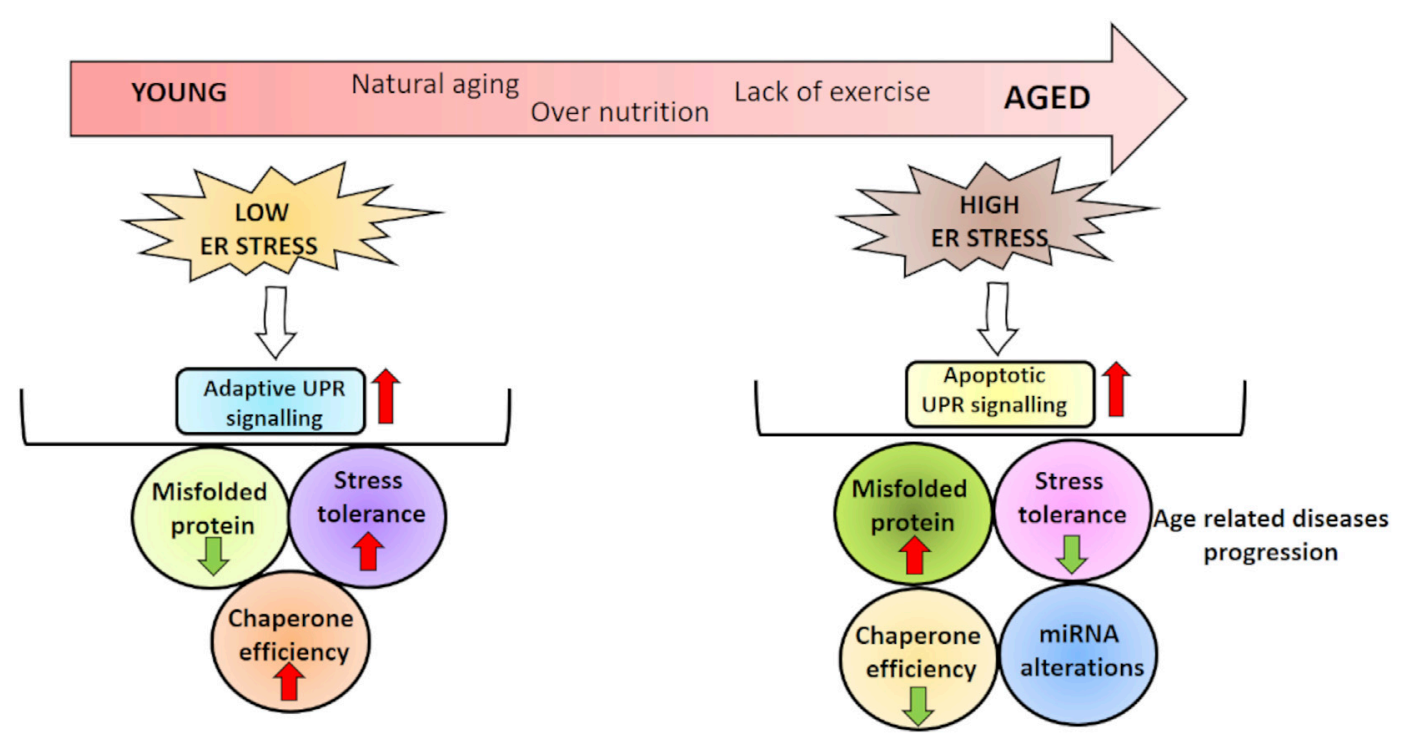

GRAPHICAL ABSTRACT |

Recognition of unfolded/misfolded proteins via endoplasmic reticulum (ER) chaperones is a well-studied process, stimulating unfolded protein response (UPR). UPR is an adaptive mechanism against ER stress, involving three signaling pathways organized via transmembrane sensors. Activation of these sensors influences various parameters that affect protein metabolism, redox homeostasis, and apoptosis. Evidence has implicated the crucial role of protein toxicity caused by aging-related UPR activity decline in age-related disorders. In this context, many studies have determined that ER chaperones (PDI, GRP78, and GRP94) and UPR signaling are decreased in aging cells (Naidoo et al., 2008).

MicroRNAs (miRNAs) are non-coding RNAs regulating the existence of their target genes through inhibition of translation or induction of mRNA degradation. miRNAs control gene expression by targeting hundreds of mRNAs. Lin-4, the first discovered miRNA in Caenorhabditis elegans, is an essential gene involved in all larval stages (Lee et al., 1993). Until now, about 2,500 miRNAs are determined in mammals and are still being discovered (O'Brien et al., 2018). Although miRNAs have a crucial role in tissue homeostasis, they also have function in metabolic and neurodegenerative diseases and CVDs (Rupaimoole and Slack, 2017). A number of miRNAs were also demonstrated to modulate the major components in UPR signaling (Byrd and Brewer, 2013). Although it is clear that ER stress and UPR activation are components of the senescent phenotype, it has not yet been fully elucidated whether ER stress/UPR is the cause or consequence of cell senescence and its relationship with miRNA in aging. The first part of our review will discuss the general principles of ER stress response as well as its interaction with miRNA and aging. In the second part, ER stress response and miRNA impairment in age-related diseases, such as metabolic disorders, neurodegenerative diseases, CVD, and cancer, will be discussed.

\section{THE ENDOPLASMIC RETICULUM STRESS RESPONSE}

The ER is a membrane-bound organelle involved in protein folding, calcium homeostasis, and lipid biosynthesis. Under normal conditions, chaperones and other proteins including GRP78, GRP94, the lectins, calnexin, calreticulin, and foldases have a central effect in the ER in performing these functions. In a variety of pathophysiological conditions, aberrant accumulation of unfolded/misfolded proteins in the ER results in ER stress and triggers the UPR pathway to degrade unfolded/misfolded proteins, suppress protein synthesis, and increase the folding ability. UPR regulation is achieved via three transmembrane proteins: 1) protein kinaselike ER kinase (PERK), 2) inositol-requiring enzyme 1 (IRE1), and 3) activating transcription factor 6 (ATF6) (Figure 1). In homeostatic conditions, GRP78 suppresses the induction of IRE1, PERK, and ATF6 by binding their luminal surface. Once ER stress is induced, IRE1, PERK, and ATF6 disassociate from GRP78, enhancing unique signaling pathways (Sozen and Ozer, 2017).

As a quick and first response against ER stress, PERK reduces protein synthesis by effecting translation in mammalian cells. Mechanistically, activated PERK phosphorylates eIF2 $\alpha$, leading to ribosome inhibition and brief attenuation of global cell translation. During prolonged stress conditions, phosphorylated eIF2a selectively stimulates ATF4, upregulating transcription of a gene encoding pro-apoptotic CHOP and GADD34. CHOP upregulates pro-apoptotic genes, while GADD34 controls protein synthesis by eIF2 $\alpha$ dephosphorylation. Therefore, besides its effect on prosurvival signaling as an initial response, PERK also induces pro-apoptotic mechanism through upregulation of CHOP and GADD34 under prolonged ER stress (Sozen et al., 2015). 


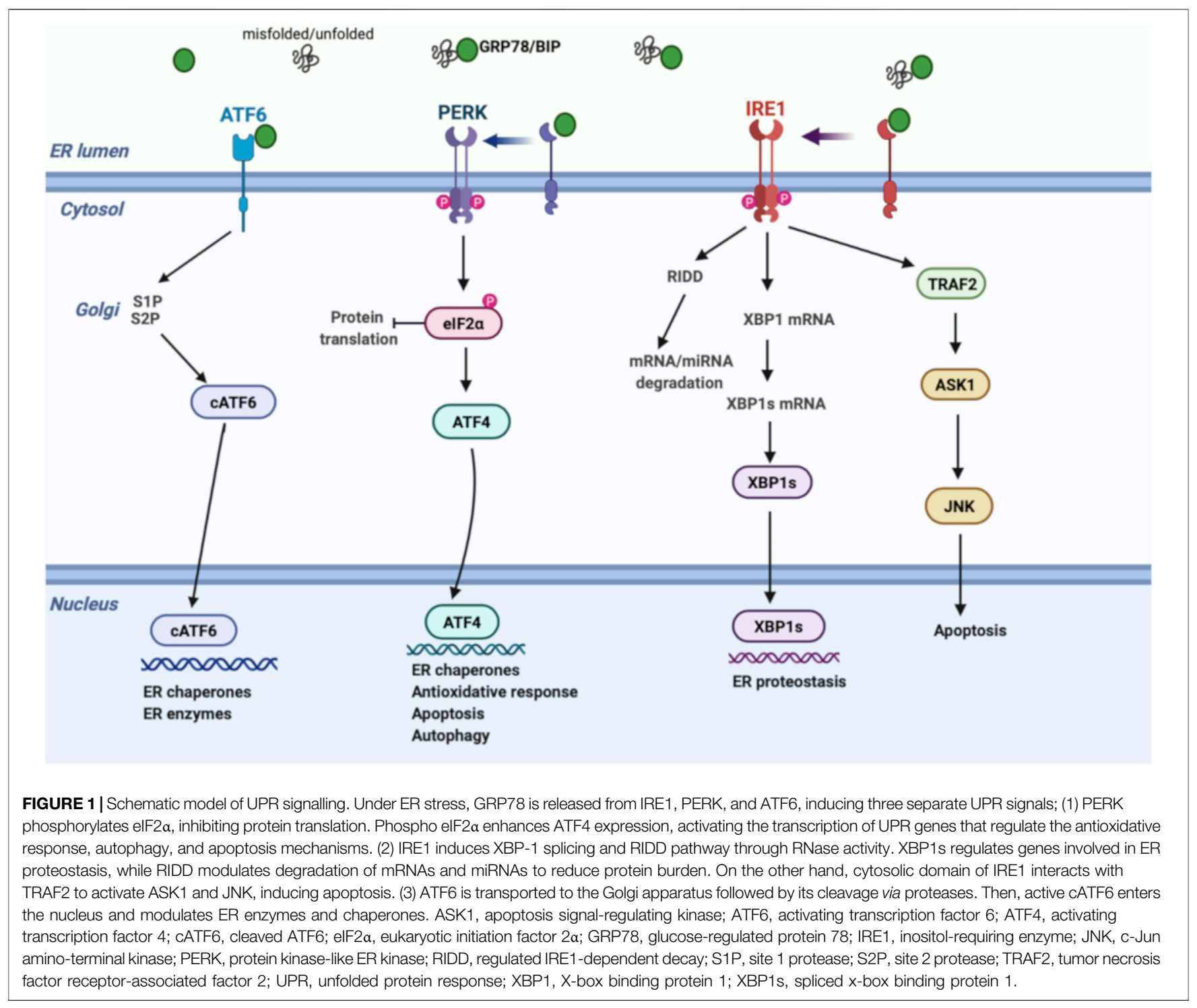

IRE1 signaling is the second most important branch of the UPR pathway. Today, it is well established that IRE1 has dual effects through its endoribonuclease and kinase domains. To restore proteostasis, cytosolic endoribonuclease domain initiates two distinct events: 1) activation of regulated IRE1dependent decay (RIDD) signaling and 2) splicing of XBP1 mRNA (Ron and Walter, 2007). RIDD pathway enhances degradation of mRNAs and prevents newly synthesized proteins from entering the ER, while XBP1 splicing upregulates chaperone gene expression. Unconventional splicing of XBP1 mRNA into XBP1s (spliced form) also interacts with certain proteins in metabolism such as FOXO1 (Zhou et al., 2011) and PI3K (Park et al., 2010). In addition, serine/threonine kinase domain of active IRE1 interacts with TRAF2 to activate ASK1, inducing apoptotic signals, including JNK and p38 (Darling and Cook, 2014).

ATF6, the third branch of the UPR, is mainly involved in expanding the functional capacity of the ER during UPR. After
ER stress is induced, ATF6 is transported to the Golgi by coat protein complex 2 and cleaved by site- 1 and site- 2 proteases. Cleaved active ATF6 then enters the nucleus and modulates ER chaperones and enzyme levels, such as PDI, GRP78, and GRP94 (Westrate et al., 2020).

\section{Endoplasmic Reticulum Stress and MicroRNA}

miRNAs are single-stranded non-coding RNAs that modulate gene activity by controlling mRNA degradation/translation. Transcription of pri-miRNA from DNA is the initial phase in miRNA biogenesis followed by the formation of pre-miRNA and mature miRNA (O'Brien et al., 2018). Often, miRNAs cause degradation or translational inhibition of mRNAs upon recognition in the $3^{\prime}$ untranslated region ( $3^{\prime}$ UTR) (Broughton et al., 2016). However, in certain cases miRNAs are determined to activate mRNA expression (Vasudevan, 2012). Changes in miRNA 


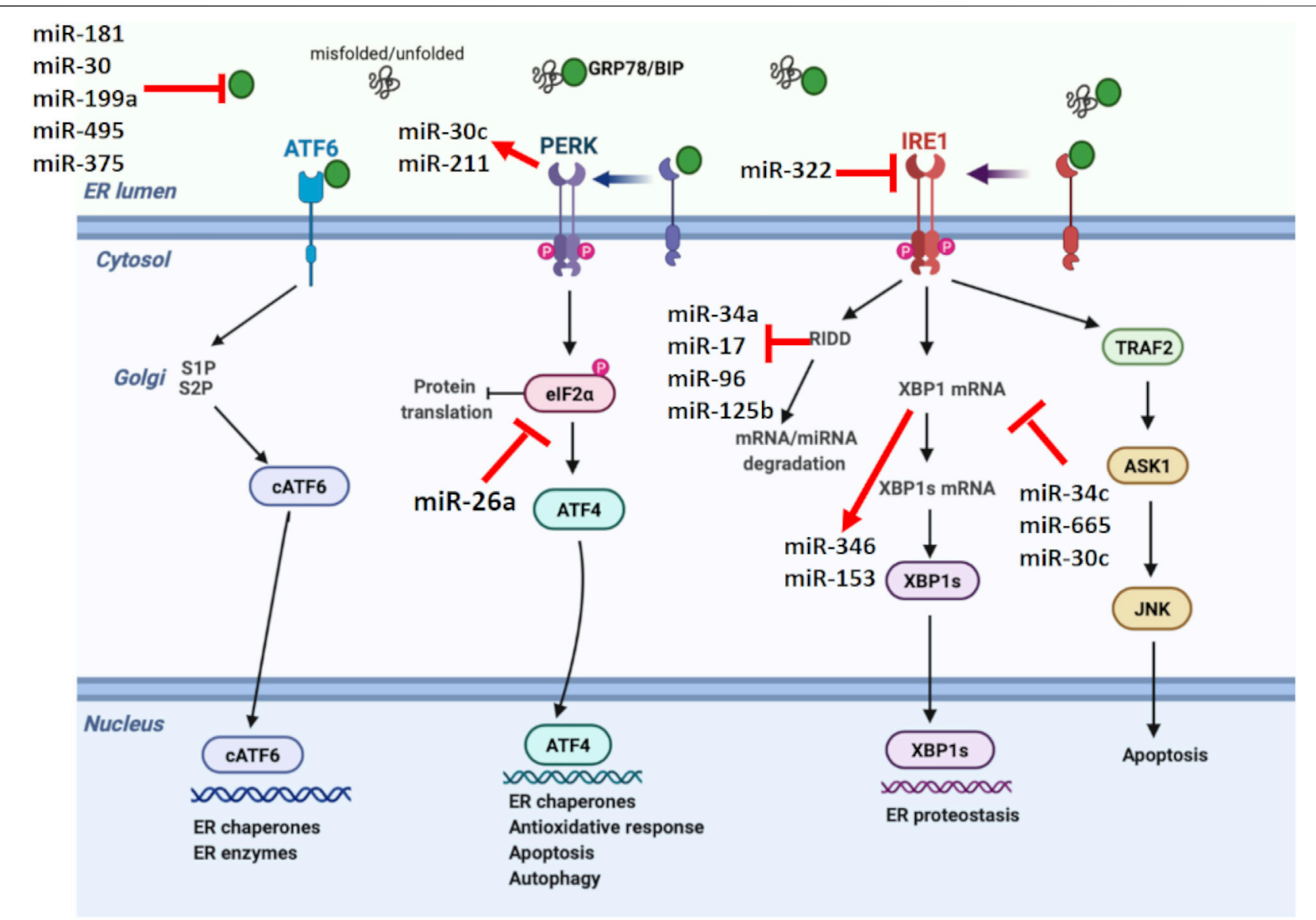

FIGURE 2 | Unfolded protein response signaling with their regulating microRNAs. miRNAs have a crucial role in shaping the UPR, while miRNA expression is also regulated by UPR. miR-181, miR-30, miR-199a, miR-495, and miR-375 negatively regulates GRP78. On the other hand, miR-322 suppresses IRE1. XBP1 and RIDD signaling, members of IRE1 branch in UPR, regulate miR-153, miR-346, miR-34a, miR-17, miR-96, and miR-125b. Additionally, miR-34c, miR-665, and miR-30c are known to target XBP1, while miR-26a suppresses elF2 $\alpha$, reducing the protein translation. Certain miRNAs also form a link between UPR branches. In this direction, PERK-mediated miR-30c activation inhibits XBP1 pathway and establishes a negative crosstalk between PERK and IRE1 branches of UPR.

expressions take a critical role in several biological mechanisms and human diseases (Paul et al., 2018). Additionally, miRNAs secreted into mammalian body fluids have been accepted as possible markers for various human diseases (Wang et al., 2016; Huang, 2017; Siracusa et al., 2018; He et al., 2020).

Related evidence in mammalian cells suggests that miRNAs are involved in shaping the ER stress, while miRNA expression is also regulated by ER stress (Figure 2) (Mesitov et al., 2017). Several miRNAs such as miR-181 family, miR-30 family, miR199a, miR-495, and miR-375 are reported to target GRP78 mRNA (Kim and Croce, 2021). In addition, it was discovered that repression of PDIA6, an activator of IRE1, by miR-322 indirectly inhibits IRE1 expression (Groenendyk et al., 2014). Certain miRNAs such as miR-34c, miR-665, and miR-30c are known to directly target XBP1 mRNA, while miR-346 and miR153 are controlled by XBP1 during ER stress (Byrd et al., 2012; Li M. et al., 2017; Bartoszewska et al., 2019). Besides miRNAs targeting UPR parameters, a couple of miRNAs are also regulated by UPR. Behrman and Walter (Behrman et al., 2011) showed that miR-711, miR-2137, miR-1897, miR-689,
miR-708, miR-712, miR-762, and miR-2132 were increased by ER stress, while miR-322, miR-503, and miR-351 were inhibited. Another study showed PERK-mediated miR-211 increase in NIH3T3 fibroblast cells, reducing apoptosis via $\mathrm{CHOP}$ inhibition (Chitnis et al., 2012).

RIDD is another pathway in which miRNA expression is modulated by ER stress (Zhang et al., 2020). Under prolonged stress conditions, RIDD degrades pre-miRNAs as well as prosurvival protein encoding mRNAs. IRE1 processes pre-miR-34 and pre-miR-200, resulting in their degradation via RIDD signaling (Wang et al., 2018). IRE1-mediated RIDD activation is also reported to cleave the anti-apoptotic miR-34a, miR-17, miR-96, and miR-125b precursors, reducing caspase 2 expression (Upton et al., 2012). Additionally, miRNAs have the ability to form a link between different UPR branches by regulating certain UPR parameters. For example, PERK-mediated miR-30c activation inhibits XBP1 pathway and establishes a negative crosstalk between IRE1 and PERK branches. Therefore, prolonged PERK activation is assumed to inhibit the prosurvival mechanism of UPR by downregulating IRE1-XBP1 
signaling (Byrd et al., 2012). The regulatory role of miR-30c between UPR branches was also demonstrated in ovarian malignant cells by inducing apoptosis through CHOP activation as well as XBP1 suppression (Rezghi Barez et al., 2021).

\section{Endoplasmic Reticulum Stress and Aging}

Aging is a complex process that impacts at the cellular and tissue levels, increasing the risk of disease/death (Gems and Partridge, 2013; Cohen, 2018). It is characterized by physiological alterations in body composition, including decreases in sex steroids and growth hormone (Barzilai et al., 2012). However, well-established hallmarks of aging are associated with several conditions that induce ER stress, including increased oxidative stress, deficiencies in mitochondrial and autophagic functions, disruptions in $\mathrm{Ca}^{2+}$ homeostasis, disorders in protein homeostasis, and energy metabolism.

Several studies have shown reduced ER chaperone levels and UPR signaling in different tissues from aged model organism. In a study, rats were divided into four groups: suckling (0-4 day old), young ( 1 month old), adult ( $>6$ months old), and old ( $>18$ months old). ATF4, GRP78, and eIF2 $\alpha$ protein expressions were evaluated and found to be decreased with age in hippocampus tissue (Hussain and Ramaiah, 2007). In accordance, GRP78, PDI, and calnexin protein expressions were downregulated, while proapoptotic caspase 12 and $\mathrm{CHOP}$ protein expressions were upregulated in hippocampus tissues of aged rats (23-26 months) compared to young (4-6 months) (Paz Gavilan et al., 2006). In addition to decreased protein folding capacity and increased proteotoxicity, accumulation of oxidized chaperones in ER was also reported in aged C57BL/6J mice (20-24 months) (Nuss et al., 2008). Another study showed decreased eIF2 $\alpha$ amount in cerebral cortex of C57BL/6J male mice aged 22-24 months (Naidoo et al., 2008). Li and Holbrook (2004) investigated ER stress in hepatocytes from young (4-5 months) and old (24-26 months) rats and reported a decrease in eIF2 $\alpha$ expression with aging. However, some studies have reported an increase in GRP78 gene expression in the heart and kidney of aged C57BL/6 mice (24 months) (Takeda et al., 2013; Sreedhar et al., 2016). Rabek et al. (2003) determined that GRP78, calreticulin, and PDI exhibited an age-related induction in liver tissue of 24-monthold mice. Ghosh et al. (2015) observed elevated GRP78, CHOP, cleaved ATF6, IRE1, and XBP-1 levels in adipose tissue stromal cells of old mice (18-20 months) compared to young (4-6 months). Furthermore, other researchers have suggested that GRP78 levels are not changed in various tissues from diabetic kidney of 22-month-old C57BL/6 mice (Wu et al., 2010; Naidoo et al., 2011; Jiao et al., 2012; Torres-Gonzalez et al., 2012) as well as skeletal muscle of 29-month-old rats (Baehr et al., 2016). While there was no change in GRP78 levels in aged Drosophila melanogaster (8 weeks), a decrease in eIF2 $\alpha$ expression was determined (Brown et al., 2014). In another study, GRP78, ATF6, and IRE1 expressions were determined to not changed in 70-year-old human muscle tissue (Ogborn et al., 2014). In addition, apoptosis and ER stress were evaluated in macrophages isolated from young (6-8 weeks) and old (16-18 months) mice, and aged macrophages were found to trigger apoptosis by inducing IRE1 activation (Song et al.,
2013). Takeda et al. (2013) determined that ATF6 was increased in kidney tissue of 24-month-old mice.

As a result, studies conducted so far have demonstrated that ER stress may be affected differently during aging. The difference in ER stress parameters might be thought to depend on the model organism used in the study or the tissue examined. However, most of the findings suggest that many components of the UPR and response to stress factors decrease with age, leading to diseases that cause or exacerbate existing diseases.

\section{Aging and MicroRNA}

miRNAs, effective players in regulating many different processes, are reported as significantly increased or decreased in aging. In Caenorhabditis elegans, miR-34 and miR-71 were found to be increased during aging, whereas miR-34 was the main contributor in the regulation of cellular senescence (Smith-Vikos and Slack, 2012). In addition, in vivo studies have demonstrated miRNA alterations in tissues such as liver, brain, muscle, and heart during aging. Maes et al. (2008) reported increased miR-93 and miR-214 levels in 33-month-old mice liver compared to 4- to 10-month-old mice liver. Another study using rat also showed an induction in miR-34a and miR-93 expressions with aging process in the liver ( $\mathrm{Li}$ et al., 2011b). Besides the liver, miRNA alterations during aging are also reported in brain tissues of animals. In a study using brain tissues of young, adult, and aged rats, sequencing was performed to determine the miRNA profiles and found 171 potential miRNAs in addition to the 547 miRNAs differentially expressed between groups (Yin et al., 2015). Additionally, expressions of miR-22, miR-101a, miR-720, and miR-721 were upregulated with aging in mouse brain (Li et al., 2011a). In skeletal muscle, miR-468, miR-7, miR-542, and miR-698 were found to be upregulated with aging, while miR-382, miR-124a, miR-181a, miR-434, miR-221, and miR455 were downregulated (Hamrick et al., 2010). miR-21 and miR22 levels were also induced in heart tissue of aged mice compared to younger ones (Zhang et al., 2012; Jazbutyte et al., 2013).

Related studies using various peripheral fluids, including plasma, serum, and saliva, in young and aged individuals have determined altered miRNA expressions. Noren Hooten et al. (2013) found that miR-181a, miR-1248, and miR-151a in the serum of the elderly (mean age 64.6 years) were significantly downregulated compared to those in younger individuals (mean age 30 years). Additionally, serum samples of Chinese individuals were collected from four different groups with mean ages of 22, 40 , 59, and 70 years, and miR-29b, miR-106b, miR-130b, miR142 , and miR-340 levels were found to decrease with age (Zhang et al., 2015). In a study conducted with 374 young and elderly populations, plasma levels of miR-126, miR-30c, miR-30b, miR210, and miR-142 were increased with age, while miR-93 was decreased (Ameling et al., 2015). Similarly, miR-24 levels in saliva were found to be increased in a mean age of 66 years compared to mean age of 21 years (Machida et al., 2015).

Besides these studies, it is important to examine centenarians as they exhibit a successful example of aging. There are a limited number of publications examining miRNA expressions in centenarians. miRNA analysis in centenarians was first reported in mononuclear cells and showed that 15,644 miRNA expressions in centenarians significantly overlapped with those in 
TABLE 1 | MicroRNA-mediated ER stress regulation during age-related diseases.

\begin{tabular}{|c|c|c|}
\hline miRNA & ER stress & Age-related diseases \\
\hline \multicolumn{3}{|l|}{ miR-199a } \\
\hline miR-30c & Reduces ER stress & Obesity (Menikdiwela et al., 2019) \\
\hline miR-708 & Induces ER stress & Obesity (Menikdiwela et al., 2019) \\
\hline \multicolumn{3}{|l|}{$\mathrm{miR}-143$} \\
\hline miR-34a & Interacts with ER stress & NAFLD (Gjorgjieva et al., 2019) \\
\hline miR-122 & Decreases UPR-mediated apoptosis & NAFLD (Gjorgjieva et al., 2019) \\
\hline miR-30 & Downregulates of $\mathrm{XBP}-1$ expression & NAFLD (Gjorgjieva et al., 2019) \\
\hline miR-26a & Targets the eukaryotic initiation factor $2 \alpha$ and decrease ER stress and hepatic steatosis & Hepatic steatosis (Xu et al., 2021) \\
\hline miR-99b & Induces ER stress & Alzheimer's disease (Ye at al., 2015) \\
\hline \multicolumn{3}{|l|}{ miR-100 } \\
\hline $\operatorname{miR}-16-1$ & Inhibits Hsp70 and promotes $a$-synuclein aggregation & Parkinson's disease (Zhang and Cheng, 2014) \\
\hline miR-7 & Reduces ER stress & Parkinson's disease (Shen et al., 2021) \\
\hline miR-29a & Induces ER stress & Amyloid lateral sclerosis (Nolan et al., 2014) \\
\hline miR-103 & Induces ER stress & Atherosclerosis (Jiang et al., 2020) \\
\hline miR-451-a & Induces ER stress & Colorectal cancer (Xu et al., 2019) \\
\hline miR-663 & Induces ER stress & Hepatocellular carcinoma (Huang et al., 2016) \\
\hline
\end{tabular}

young individuals but not in octogenarians (Serna et al., 2012). The same group published another study, and they showed that RNA Pol II, Dicer, Drosha, and Exportin 5 activities, crucial players in miRNA biogenesis, were upregulated in centenarians compared to octogenarians (Borras et al., 2017). Additionally, Gombar et al. (2012) evaluated the miRNAs in B cells of Ashkenazi Jewish centenarians by sequencing and determined 22 increased miRNAs in addition to 2 reduced miRNAs over centenarians compared to mean age of 50 years. Beside those findings, miR-21, miR-425, and miR-212 were shown to be reduced in centenarians compared to those with an age between 30 and 50 years (Balzano et al., 2017). Collectively, numerous studies greatly expanded our understanding of the effect of miRNAs during aging. Although these findings indicate miRNA alterations, additional studies are needed to inspire the use of miRNAs therapeutically.

\section{Aging, Endoplasmic Reticulum Stress, and MicroRNA}

Involvement of miRNAs in regulating stress-induced responses (Ong, et al., 2019) and the role of UPR in controlling proteostasis in aging models (Martinez et al., 2017) are reported in a variety of studies. Besides the theories and findings about the different roles of ER stress and miRNA in aging, the limited number of studies discovering ER stress and miRNA impairment in aging makes it difficult to make a definitive judgement. Therefore, the question arises whether the ER stress-miRNA relationship is involved in the initiation or maintenance of aging characteristics. Due to the limited information on this issue, the potential effect of ER stress and miRNA on aging as well as possible interaction points will be discussed in this part. IRE1-mediated RIDD activation might be an important process in this context. RIDD activation is determined in ER stress-mediated degradation of various miRNA families, including miR-34, miR-200, miR-17, miR-96, and miR-125b (Upton et al., 2012; Wang et al., 2018). In drosophila, miRNA-mediated alterations in chaperone proteins are reported to have a crucial role in brain aging. miRNA-34 increase determined in this study is reported to be an essential process required for healthy brain aging in drosophila. Researchers have also showed that miR-34 modulates the chaperone system and prevents neurodegeneration by inhibiting polycomb repressor complex 2 in aged drosophila brain (Kennerdell et al., 2018). However, they did not indicate the role of RIDD in this process. We believe it would be beneficial to investigate miR-34 and other miRNAs in aging by associating with RIDD. Additionally, miRNAs that mediate a link between different branches of UPR should be evaluated during aging. In this context, miR-181 family, miR-30 family, miR-199a, miR-495, miR-375, miR-322, miR-34c, miR-665, miR-346, miR-153, and miR-211 might provide useful information in encouraging miRNA-mediated silencing therapy as a beneficial strategy against ER stress-induced disease development.

Compared to the aging process, the effect of miRNA-ER stress in age-related diseases has been more investigated. As stated in the second part of our review, multiple studies have revealed ER stress-miRNA interaction in metabolic disorders, neurodegenerative diseases, and CVDs and cancer in many aspects. We believe that studying these aspects of age-related diseases during the aging process will be important in providing new perspectives. In summary, although many lines of evidence support a strong connection between aging, UPR, and miRNA, experiments are further needed to better characterize molecular and functional links between these, especially in in vitro and in vivo models in which data are very few presently. A comprehensive understanding of the relationship between aging miRNA and ER stress is thought to help improve this universal process that compromises our quality of life.

\section{ENDOPLASMIC RETICULUM STRESS AND MICRORNA ALTERATION IN AGE-RELATED DISEASES}

Studies have identified miRNAs as key regulators of many genes involved in cellular signaling pathways (Wang Y. et al., 2008). As shown in Tables $\mathbf{1}$ and 2, various in vitro and in vivo studies have 
TABLE 2 | ER stress-mediated miRNA regulation during age-related diseases.

ER stress

IRE1a inhibition

PERK

UPR activation

RIDD activation
miRNA

Induces miR-34a

Suppresses miR-24

Inhibits mir 199a and mir214

Degrades pre-miR-200 and pre-miR-34
Functions

Protective effects against A $\beta$-induced injury in SH-SY5Y cells ( $L i$ et al., 2019)

Protection against mitochondrial dysfunction in heart failure (Shimizu et al., 2020)

Regulates tumor survival and progression (Duan et al., 2012)

Prevents hepatic steatosis (Wang et al., 2018)

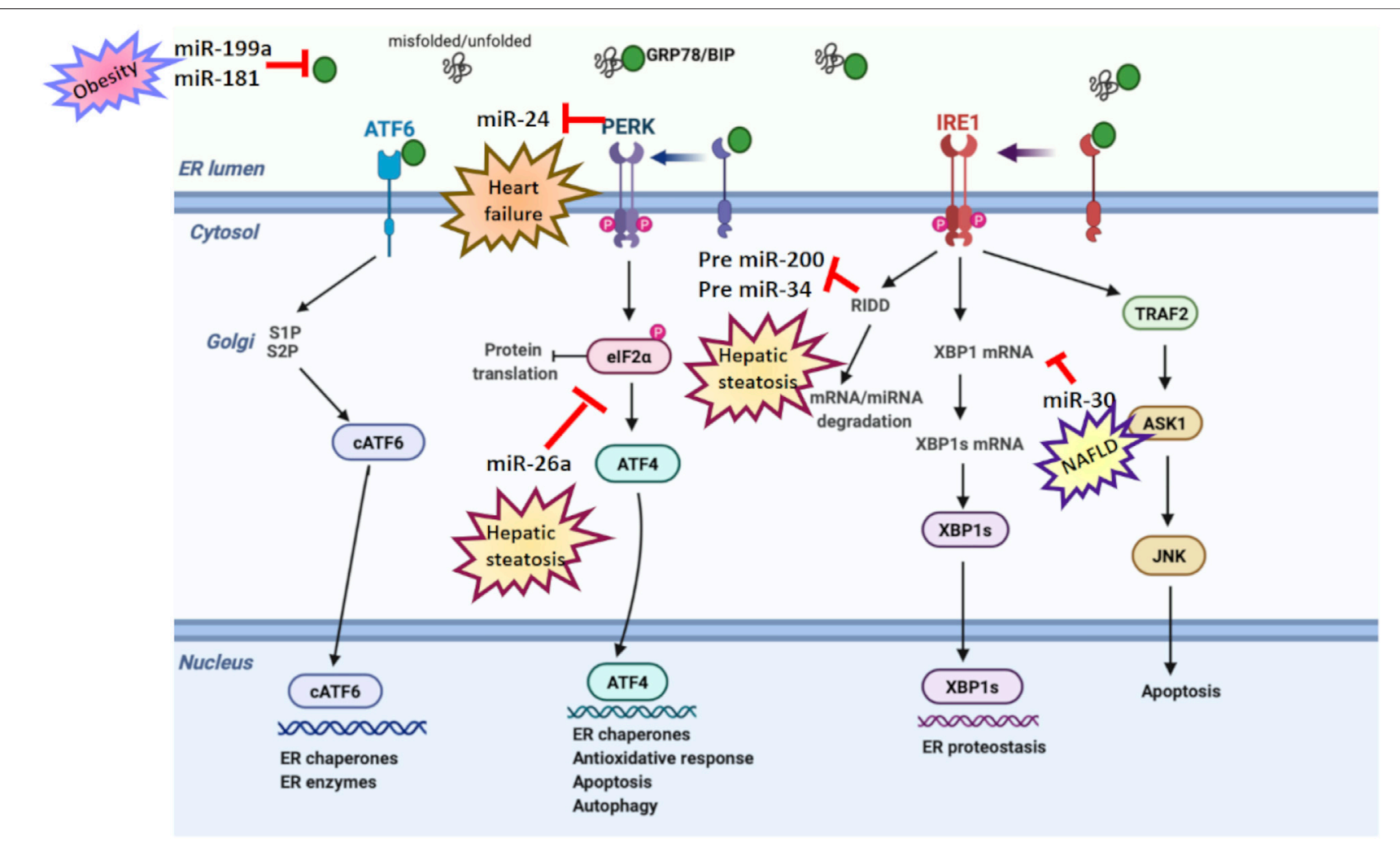

FIGURE 3 | ER stress and microRNA relation in age-related diseases. Various studies have reported a dual relation between miRNA and ER stress in age-related disorders. miR-199a and miR-181 suppress GRP78 expression in obesity. miR-30 downregulates XBP-1 expression in NAFLD. miR-26a reduces elF2 $\alpha$ in hepatic steatosis. However, PERK suppresses miR-24 in heart failure, while RIDD activation degrades pre-miR-200 and pre-miR-34 in hepatic steatosis.

reported a dual relationship between miRNA and ER stress in age-related diseases. In addition, the relation between ER stress and miRNA in age-related diseases is shown in Figure 3. In this part of our review, we will highlight ER stress and miRNA impairment in age-related diseases, including metabolic disorders, neurodegenerative diseases, and CVDs as well as cancer.

\section{Metabolic Disorders}

Metabolic disorders generate serious threats to human health and lead to severe chronic diseases such as obesity, diabetes, and fatty liver (Lemmer et al., 2021). While the risk of developing metabolic disorders increases with age, the aging process is accelerated in the presence of these diseases (Guarner-Lans et al., 2011). Obesity, insulin resistance, inflammation, and hypertension, which increase in prevalence during aging, also contribute to metabolic syndrome (Diaz et al., 2019).
A number of diseases, including metabolic disorders, have been found to be associated with ER abnormalities since ER is the major organelle in regulating calcium signaling, protein and lipid metabolism, and gluconeogenesis. Obesity and insulin resistance, two major metabolic disorders occurring all around the world, are also related to ER stress (Han et al., 2006; Hotamisligil, 2006). JNK and NFKB pathways are principal inflammatory signals linked to disturbance in insulin action (Deng et al., 2004). IRE1 is associated with TRAF2-mediated activation of JNK as described above (Sozen and Ozer, 2017), while NFkB signaling is mediated with activation of both IRE1 and PERK, through different mechanisms. IRE1-mediated IKK induction through TRAF2 activation triggers $\mathrm{NF \kappa B}$ signaling and stimulates inflammatory genes (Salminen et al., 2020). PERK-mediated eIF2 $\alpha$ kinase also stimulates NFKB signaling (Jiang et al., 2003). Insulin-receptor substrate 1 (IRS1), activated by phosphorylation of insulin receptors, is crucial in the 
distribution and modulation of insulin signaling. ER stress has also been demonstrated to reduce insulin receptor signaling by activating JNK and induce insulin resistance (Koh et al., 2013; Brown et al., 2020). IRS1 was suppressed by ER stress-mediated JNK hyperactivation in the liver tissue of obese mice (Ozcan et al., 2004). The capacity of ER stress in disturbing IRS1 induction is also reported in brain tissue of obese rats (Liang et al., 2015).

Expression of miRNAs is differentially modulated in insulin-sensitive tissues during metabolic disorders, including type 2 diabetes (Menikdiwela et al., 2021). In this scope, it has been shown that the regulation of UPR branches is carried out by a couple of miRNAs. GRP78 expression has been determined to be suppressed by miR-181a and miR-199a (Mesitov et al., 2017). Menikdiwela et al. (2019) also showed ER stress signaling is reduced by miR-30c, while it is induced by miR-708 and miR-143 in obese mice. Further, miRNAs have been known to have a crucial effect in fatty liver diseases (Bozaykut et al., 2016). However, there are limited studies examining ER stress-miRNA relationship in hepatocytes (Xu et al., 2021). miR-34a, miR-122, and miR30 were determined to enhance the development and progression of nonalcoholic fatty liver disease (NAFLD) via interacting with ER stress (Gjorgjieva et al., 2019). miR-122mediated UPR downregulation resulted in reduced apoptosis in human hepatoma cells (Yang et al., 2011), while miR-34aincreased GRP78 levels activated ER stress in mouse liver (Stacchiotti et al., 2019). RIDD-mediated pre-miR-200 and pre-miR-34 degradation are involved in hepatic steatosis (Wang et al., 2018), while miR-23a-mediated ER stress activation supported hepatocarcinogenesis (Liu et al., 2019). miR-26a is other miRNA that was found to reduce ER stress and hepatic steatosis in murine primary hepatocytes, human hepatoma cells, and mice fed a high-fat diet. Mechanistically, miR-26a directly targets eIF2 $\alpha$, reducing the protein burden by inhibiting translation (Xu et al., 2021).

\section{Neurodegenerative Diseases}

A certain feature of neurodegenerative diseases is the formation of misfolded protein aggregates that affect neuronal death. These diseases, including Alzheimer's disease (AD), Parkinson's disease (PD), amyloid lateral sclerosis (ALS), and Huntington's, are associated with aging processes that normally occur later in life (Lindholm et al., 2006). Given the prevalence in the elderly population, brain aging may form a continuum with neurodegeneration (Santulli et al., 2015). AD and PD prevalence is high in the elderly population, and also, the risk of developing these diseases enhances by age (Hou et al., 2019). Recent studies determined the protective effect of initial UPR steps, while prolonged activation induced apoptotic signaling (Perri et al., 2015). It has been determined that UPR parameters, including GRP78, IRE1, ATF6, PERK, eIF2 $\alpha$, and $\mathrm{CHOP}$, are increased in patients with $\mathrm{AD}$ (Garcia-Gonzalez et al., 2018), PD (Gerakis and Hetz, 2018), ALS (Prell et al., 2019), and prion diseases (Lindholm et al., 2017).

$\mathrm{AD}$ is characterized by accumulation of amyloid- $\beta$ (A $\beta)$ plaques that are mediated by $\beta$-secretase (BACE) and $\gamma$ secretase from cleavage of amyloid $\beta$-precursor protein (APP)
(Jiang et al., 2012). Association between ER stress and synthesis of $\mathrm{A} \beta, \mathrm{BACE}$, and $\gamma$-secretases has been well identified (Walter and Ron, 2011). In this context, UPR activation upregulated PERK, eIF2 $\alpha$, and IRE1 levels in the temporal cortex and hippocampus (Xiang et al., 2017). In primary rat embryo neuronal cultures, UPR also induced the activity of glycogen synthase kinase $3 p$, leading to tau phosphorylation (Resende et al., 2008).

$\mathrm{PD}$ is another neurodegenerative disease defined by enhanced dopaminergic neuron loss and formation of modified a-synuclein aggregates with a prevalence increasing with age (de Lau and Breteler, 2006). Numerous studies have reported ER stress in $\mathrm{PD}$ pathogenesis and determined its role in a-synuclein accumulation in PD patients (Hoozemans et al., 2007). ATF6 deficiency enhanced the dopaminergic neuron damage, triggering PD development in mice (Egawa et al., 2011). In vivo studies have also demonstrated the capacity of IRE1-XBP1 signaling in controlling dopaminergic neuron survival (Valdes et al., 2014).

In mammals, more miRNAs are expressed in the brain than in many other tissues, and thus miRNAs play key functions in neuronal development and in the pathogenesis of neurodegenerative diseases (Maciotta et al., 2013; Rajgor and Hanley, 2016). Related studies determined abnormal miRNA expression in brains of $\mathrm{AD}$ and suggested the involvement of miRNA alteration in tau phosphorylation or $A \beta$ deposition ( $\mathrm{Wu}$ et al., 2016). miR-101 modulated APP expression in rat hippocampal neurons (Vilardo et al., 2010), while miRNA-107, which targets BACE1, was lower in AD patients (Wang W.-X. et al., 2008). Another study with middle-aged rats determined that miR-17, miR-106b, miR-153, and miR-101 expressions, which target APP, were reduced in brain tissue (Che et al., 2014). Decreased miR-186 levels in the cortex of aged mice were also found to be related to BACE1 expression (Kim et al., 2016). A study with $\mathrm{AD}$ patients showed the downregulated miRNA-29a/b-1 expression in the cortex, associated with BACE1 protein (Hebert et al., 2008). miR-141, $\mathrm{miR}-200 \mathrm{a} / \mathrm{b} / \mathrm{c}$, and $\mathrm{miR}-429$ were found to be increased in earlyage $\mathrm{AD}$ in mice (Wu et al., 2016). However, a number of researches revealed possible interaction between ER stress and miRNA alterations during AD pathogenesis. For example, ER stress inhibits PTEN expression by inducing miR-200c to protect neurons against $A \beta$ toxicity in the initial step of $A \beta$ damage $(\mathrm{Wu}$ et al., 2016). Ye et al. showed that miR-99b and miR-100 induced ER stress in AD mice (Ye et al., 2015). On the other hand, miR34a upregulation in SH-SY5Y cells has been reported to be protective against $A \beta$-mediated injury by causing IRE1 inhibition (Li et al., 2019).

In addition, various miRNAs involved in the pathogenesis of PD have been identified. Decreased miR-34c and miR-34b expression in SH-SY5Y cells were demonstrated to contribute to $\mathrm{PD}$ pathogenesis by increasing a-synuclein (Kabaria et al., 2015). Zhang and Cheng (2014) determined the contribution of miR-16-1 to PD development by inhibiting Hsp70 levels and inducing a-synuclein accumulations in SH-SY5Y cells. On the contrary, miR-7-mediated ER stress suppression in SH-SY5Y has been determined to be protective against PD (Shen et al., 2021). 
TABLE 3 | Changing views on ER stress.

\section{Past}

GRP78 mRNA or protein induction is a gold standard ER stress marker

elF2 $a$ phosphorylation inhibits only $5^{\prime}$ methylguanylate (5me-G) cap-dependent mRNA translation

IRE1 RNase splices XBP1 mRNA, which encodes a potent transcription factor that activates expression of UPR target genes involved in ER proteostasis and cell pathophysiology

miRNAs induce ER stress

IRE1, PERK, and ATF6 form three separate branches of the UPR

\section{Present}

GRP78 is a poor ER stress marker as it is a stable and abundant protein. Sensitive real-time markers, including phospho IRE1, phospho PERK, and activated ATF6, should be evaluated

Phosphorylated elF2 $\alpha$ inhibits both cap-dependent and cap-independent mRNA translation

IRE1 RNase can also cleave mRNAs and precursor microRNAs leading to their degradation through regulated IRE1-dependent decay (RIDD), which modulates the protein folding load, cell metabolism, and apoptosis miRNAs can also be processed during ER stress

PERK generates a crosstalk with XBP1 by regulating the expression of various miRNAs

\section{Cardiovascular Diseases}

Aging is another important risk factor in CVDs besides the obesity and diabetes. The prevalence of CVDs, including atherosclerosis, heart failure, and stroke, has been known to increase by age in both women and men, linking to a number of factors such as apoptosis, oxidative stress, overall myocardial deterioration/degeneration, and inflammation (Benjamin et al., 2019).

The ER has a critical role in the normal function of the heart by providing the proper protein synthesis and folding in cardiomyocytes (Sozen et al., 2015; Sozen et al., 2020). Inflammation, metabolic disorder, and hypoxia occurring in CVD may trigger ER stress by affecting protein folding mechanisms (Diaz-Bulnes et al., 2019). Recent studies have reported increased levels of GRP78, XBP1s, CHOP, and ATF4 in cardiomyocytes of patients with heart failure (Ortega et al., 2014; Duan et al., 2015). Induced ER stress parameters might reflect involvement of UPR in promoting cardiac heart failure and hypertrophy, supporting the therapeutic value of ER stress targeting to reverse or reduce CVDs (Yao et al., 2017). Dual relationship between miRNA and ER stress in CVD is also reported (Maurel and Chevet, 2013). Knockdown of miR-30 in rat aorta vascular smooth cells and ventricular cells activated ER stress and induced ATF6, GRP78, caspase-12, and CHOP expressions (Chen et al., 2014). Additionally, miR-124 downregulation in cardiomyocytes reduced GRP78 and calreticulin (Bao et al., 2017), while miR-1283 inhibition in HUVEC cell line inhibited PERK/ATF4 activity and apoptosis, inflammation, and endothelial injury in heart tissue of mice (He et al., 2016). Another study determined the inhibitory effect of miR-133a against ER stress and apoptosis in rat cardiomyocyte (H9C2) cell line (Ren et al., 2019).

However, certain miRNAs may promote ER stress and predispose to CVDs (Ren et al., 2021). For instance, miR-103 in endothelial cells was highly expressed in atherosclerotic mice and upregulated inflammation and ER stress through miR103-PTEN-MAPK axis (Jiang et al., 2020). Additionally, PERK-mediated miR-24 downregulation was reported to reduce mitochondrial dysfunction in heart failure (Shimizu et al., 2020).

\section{Cancer}

The incidence of cancer in individuals over the age of 65 years has increased in most countries over the past decade. The risk of cancer in men and women increases approximately seven times with age compared to the young population in all types of cancer (Kumar et al., 2017). Extrinsic stresses and oncogenic activation exerted by the tumor environment are determined to induce UPR activation by increasing misfolded proteins. Numerous researchers have found the involvement of ER stress and UPR in many cancer types, including liver, lung, breast, glioma, and colorectal cancer (Shuda et al., 2003; Uramoto et al., 2005; Scriven et al., 2009; Auf et al., 2010; Jin et al., 2016). Cancer cells can evade prolonged UPR signal-mediated apoptosis and use UPR to stimulate metastasis and proliferation (Wang et al., 2010; Madden et al., 2019). However, UPR signaling might also limit the effectiveness of chemotherapy by generating chemoresistance (Chen et al., 2017; Salaroglio et al., 2017). Li X.-X. et al. (2017) found that silencing IRE1 in colon cancer cell line inhibited cell proliferation. Similarly, inhibition of IRE1 RNase activity decreased their proliferation capacity in breast cancer cells (Logue et al., 2018).

To date, certain miRNAs that play a role as an oncogene or tumor suppressor have been identified and characterized (Dragomir et al., 2018). miR-16 and miR-15, the first described cancer-related miRNAs, stimulate cancer development by decreasing anti-apoptotic BCL2 gene in chronic lymphocytic leukemia (Calin et al., 2002). Numerous studies using UPRactivated cancer cells have also determined miRNAs as a key modulator in cell death mechanisms. Therefore, IRE1 and ATF6 activation regulates tumor survival and progression by inhibiting miR-199a and miR-214 in human hepatocellular carcinoma cell lines, including HepG2 and SMMC-7721 (Duan et al., 2012). Additionally, most miRNAs in ER stress-induced cell death are determined to be involved in the PERK-eIF2 $\alpha-\mathrm{CHOP}$ pathway (Kim and Croce, 2021). Xu et al. (2019) showed that miR-451a overexpression activates apoptosis by inducing PERK/elF2 $\alpha /$ ATF4/CHOP signaling in colorectal cancer cells, HCT116, and SW620. On the contrary, Huang et al. (2016) showed that ER stress-mediated induction miR-663 stimulates cell proliferation and reduces apoptosis in hepatocellular carcinoma cell.

\section{CONCLUSION}

Impairments in ER-associated functions as well as alterations in miRNA levels in the aging process were reported to promote the progress of many age-related diseases. With more research conducted by basic and clinical scientists, more links will be 
established between the UPR and aging process. Recent advances arising from in vitro and in vivo studies have updated traditional principles of ER stress, changing our view of managing ER stressrelated diseases (Table 3 ). In the light of the findings determining UPR/miRNA interaction in age-related diseases, miRNA therapy might be used to normalize gene expression alterations in the cells. So far, although the large number of studies using miRNAs greatly expanded our knowledge of their control over age-related diseases, their use in specific therapy is largely unknown. Despite these valuable findings, further studies are needed to determine mechanistic insights of ER stress and miRNA impairment as well as uncover additional miRNAs that might be considered as potential targets to open new doors in therapeutic approaches for aging and age-related diseases.

\section{REFERENCES}

Ameling, S., Kacprowski, T., Chilukoti, R. K., Malsch, C., Liebscher, V., Suhre, K., et al. (2015). Associations of Circulating Plasma microRNAs with Age, Body Mass index and Sex in a Population-Based Study. BMC Med. Genomics 8, 61. doi:10.1186/s12920-015-0136-7

Auf, G., Jabouille, A., Guerit, S., Pineau, R., Delugin, M., Bouchecareilh, M., et al. (2010). Inositol-requiring Enzyme 1 Is a Key Regulator of Angiogenesis and Invasion in Malignant Glioma. Proc. Natl. Acad. Sci. 107, 15553-15558. doi:10.1073/pnas.0914072107

Baehr, L. M., West, D. W. D., Marcotte, G., Marshall, A. G., De Sousa, L. G., Baar, K., et al. (2016). Age-related Deficits in Skeletal Muscle Recovery Following Disuse Are Associated with Neuromuscular junction Instability and ER Stress, Not Impaired Protein Synthesis. Aging 8, 127-146. doi:10.18632/aging.100879

Balzano, F., Deiana, M., Dei Giudici, S., Oggiano, A., Pasella, S., Pinna, S., et al. (2017). MicroRNA Expression Analysis of Centenarians and Rheumatoid Arthritis Patients Reveals a Common Expression Pattern. Int. J. Med. Sci. 14, 622-628. doi:10.7150/ijms.18972

Bao, Q., Chen, L., Li, J., Zhao, M., Wu, S., Wu, W., et al. (2017). Role of microRNA124 in Cardiomyocyte Hypertrophy Inducedby Angiotensin II. Cel Mol Biol (Noisy-le-grand) 63, 23-27. doi:10.14715/cmb/2017.63.4.4

Bartoszewska, S., Cabaj, A., Dąbrowski, M., Collawn, J. F., and Bartoszewski, R. (2019). miR-34c-5p Modulates X-box-Binding Protein 1 (XBP1) Expression during the Adaptive Phase of the Unfolded Protein Response. FASEB j. 33, 11541-11554. doi:10.1096/fj.201900600RR

Barzilai, N., Huffman, D. M., Muzumdar, R. H., and Bartke, A. (2012). The Critical Role of Metabolic Pathways in Aging. Diabetes 61, 1315-1322. doi:10.2337/ db11-1300

Behrman, S., Acosta-Alvear, D., and Walter, P. (2011). A CHOP-Regulated microRNA Controls Rhodopsin Expression. J. Cel Biol 192, 919-927. doi:10.1083/jcb.201010055

Benjamin, E. J., Muntner, P., Alonso, A., Bittencourt, M. S., Callaway, C. W., Carson, A. P., et al. (2019). Heart Disease and Stroke Statistics-2019 Update: A Report from the American Heart Association. Circulation 139, e56-e528. doi:10.1161/CIR.0000000000000659

Borrás, C., Serna, E., Gambini, J., Inglés, M., and Vina, J. (2017). Centenarians Maintain miRNA Biogenesis Pathway while it Is Impaired in Octogenarians. Mech. Ageing Dev. 168, 54-57. doi:10.1016/j.mad.2017.07.003

Bozaykut, P., Sahin, A., Karademir, B., and Ozer, N. K. (2016). Endoplasmic Reticulum Stress Related Molecular Mechanisms in Nonalcoholic Steatohepatitis. Mech. Ageing Dev. 157, 17-29. doi:10.1016/j.mad.2016.07.001

Broughton, J. P., Lovci, M. T., Huang, J. L., Yeo, G. W., and Pasquinelli, A. E. (2016). Pairing beyond the Seed Supports MicroRNA Targeting Specificity. Mol. Cel 64, 320-333. doi:10.1016/j.molcel.2016.09.004

Brown, M., Dainty, S., Strudwick, N., Mihai, A. D., Watson, J. N., Dendooven, R., et al. (2020). Endoplasmic Reticulum Stress Causes Insulin Resistance by

\section{AUTHOR CONTRIBUTIONS}

NKO contributed to conception and design. TD-Y drafted the manuscript. ES and NKO revised the manuscript. All authors approved submitted version.

\section{FUNDING}

This study was funded by Marmara University Research Fund, Grant/Award Numbers: SAG-C-DRP-110915-0419 and SAGC-YLP-090517-0253 and The Scientific and Technological Research Council of Turkey (TUBITAK), Grant/Award Number: 115S464.

Inhibiting Delivery of Newly Synthesized Insulin Receptors to the Cell Surface. MBoC 31, 2597-2629. doi:10.1091/mbc.E18-01-0013

Brown, M. K., Chan, M. T., Zimmerman, J. E., Pack, A. I., Jackson, N. E., and Naidoo, N. (2014). Aging Induced Endoplasmic Reticulum Stress Alters Sleep and Sleep Homeostasis. Neurobiol. Aging 35, 1431-1441. doi:10.1016/ j.neurobiolaging.2013.12.005

Byrd, A. E., Aragon, I. V., and Brewer, J. W. (2012). MicroRNA-30c-2* Limits Expression of Proadaptive Factor XBP1 in the Unfolded Protein Response. J. Cel Biol 196, 689-698. doi:10.1083/jcb.201201077

Byrd, A. E., and Brewer, J. W. (2013). Micro(RNA)managing Endoplasmic Reticulum Stress. IUBMB Life 65, 373-381. doi:10.1002/iub.1151

Calin, G. A., Dumitru, C. D., Shimizu, M., Bichi, R., Zupo, S., Noch, E., et al. (2002). Nonlinear Partial Differential Equations and Applications: Frequent Deletions and Down-Regulation of Micro- RNA Genes miR15 and miR16 at 13q14 in Chronic Lymphocytic Leukemia. Proc. Natl. Acad. Sci. 99, 15524-15529. doi:10.1073/pnas.242606799

Che, H., Sun, L.-H., Guo, F., Niu, H.-F., Su, X.-L., Bao, Y.-N., et al. (2014). Expression of Amyloid-Associated miRNAs in Both the Forebrain Cortex and hippocampus of Middle-Aged Rat. Cell Physiol Biochem 33, 11-22. doi:10.1159/ 000356646

Chen, D., Rauh, M., Buchfelder, M., Eyupoglu, I. Y., and Savaskan, N. (2017). The Oxido-Metabolic Driver ATF4 Enhances Temozolamide Chemo-Resistance in Human Gliomas. Oncotarget 8, 51164-51176. doi:10.18632/oncotarget.17737

Chen, M., Ma, G., Yue, Y., Wei, Y., Li, Q., Tong, Z., et al. (2014). Downregulation of the miR-30 Family microRNAs Contributes to Endoplasmic Reticulum Stress in Cardiac Muscle and Vascular Smooth Muscle Cells. Int. J. Cardiol. 173, 65-73. doi:10.1016/j.ijcard.2014.02.007

Chitnis, N. S., Pytel, D., Bobrovnikova-Marjon, E., Pant, D., Zheng, H., Maas, N. L., et al. (2012). miR-211 Is a Prosurvival microRNA that Regulates Chop Expression in a PERK-dependent Manner. Mol. Cel 48, 353-364. doi:10.1016/j.molcel.2012.08.025

Cohen, A. A. (2018). Aging across the Tree of Life: The Importance of a Comparative Perspective for the Use of Animal Models in Aging. Biochim. Biophys. Acta (Bba) - Mol. Basis Dis. 1864, 2680-2689. doi:10.1016/ j.bbadis.2017.05.028

Darling, N. J., and Cook, S. J. (2014). The Role of MAPK Signalling Pathways in the Response to Endoplasmic Reticulum Stress. Biochim. Biophys. Acta (Bba) - Mol. Cel Res. 1843, 2150-2163. doi:10.1016/j.bbamcr.2014.01.009

De Lau, L. M., and Breteler, M. M. (2006). Epidemiology of Parkinson's Disease. Lancet Neurol. 5, 525-535. doi:10.1016/S1474-4422(06)70471-9

Deng, J., Lu, P. D., Zhang, Y., Scheuner, D., Kaufman, R. J., Sonenberg, N., et al. (2004). Translational Repression Mediates Activation of Nuclear Factor Kappa B by Phosphorylated Translation Initiation Factor 2. Mol. Cel Biol 24, 10161-10168. doi:10.1128/MCB.24.23.10161-10168.2004

Díaz, A., López-Grueso, R., Gambini, J., Monleón, D., Mas-Bargues, C., Abdelaziz, K. M., et al. (2019). Sex Differences in Age-Associated Type 2 Diabetes in RatsRole of Estrogens and Oxidative Stress. Oxidative Med. Cell Longevity 2019, 1-13. doi:10.1155/2019/6734836 
Díaz-Bulnes, P., Saiz, M. L., López-Larrea, C., and Rodríguez, R. M. (2019). Crosstalk between Hypoxia and ER Stress Response: A Key Regulator of Macrophage Polarization. Front. Immunol. 10, 2951. doi:10.3389/ fimmu.2019.02951

Dragomir, M., Mafra, A., Dias, S., Vasilescu, C., and Calin, G. (2018). Using microRNA Networks to Understand Cancer. Int. J. Mol. Sci. 19, 1871. doi:10.3390/ijms19071871

Duan, Q., Chen, C., Yang, L., Li, N., Gong, W., Li, S., et al. (2015). MicroRNA Regulation of Unfolded Protein Response Transcription Factor XBP1 in the Progression of Cardiac Hypertrophy and Heart Failure In Vivo. J. Transl Med. 13, 363. doi:10.1186/s12967-015-0725-4

Duan, Q., Wang, X., Gong, W., Ni, L., Chen, C., He, X., et al. (2012). ER Stress Negatively Modulates the Expression of the miR-199a/214 Cluster to Regulates Tumor Survival and Progression in Human Hepatocellular Cancer. PLoS One 7, e31518. doi:10.1371/journal.pone.0031518

Egawa, N., Yamamoto, K., Inoue, H., Hikawa, R., Nishi, K., Mori, K., et al. (2011). The Endoplasmic Reticulum Stress Sensor, ATF6a, Protects against Neurotoxin-Induced Dopaminergic Neuronal Death. J. Biol. Chem. 286, 7947-7957. doi:10.1074/jbc.M110.156430

García-González, P., Cabral-Miranda, F., Hetz, C., and Osorio, F. (2018). Interplay between the Unfolded Protein Response and Immune Function in the Development of Neurodegenerative Diseases. Front. Immunol. 9, 2541. doi:10.3389/fimmu.2018.02541

Gems, D., and Partridge, L. (2013). Genetics of Longevity in Model Organisms: Debates and Paradigm Shifts. Annu. Rev. Physiol. 75, 621-644. doi:10.1146/ annurev-physiol-030212-183712

Gerakis, Y., and Hetz, C. (2018). Emerging Roles of ER Stress in the Etiology and Pathogenesis of Alzheimer's Disease. FEBS J. 285, 995-1011. doi:10.1111/ febs. 14332

Ghosh, A. K., Garg, S. K., Mau, T., O'Brien, M., Liu, J., and Yung, R. (2015). Elevated Endoplasmic Reticulum Stress Response Contributes to Adipose Tissue Inflammation in Aging. Gerona 70, 1320-1329. doi:10.1093/gerona/glu186

Gjorgiieva, M., Sobolewski, C., Dolicka, D., Correia De Sousa, M., and Foti, M. (2019). miRNAs and NAFLD: from Pathophysiology to Therapy. Gut 68, 2065-2079. doi:10.1136/gutjnl-2018-318146

Gombar, S., Jung, H. J., Dong, F., Calder, B., Atzmon, G., Barzilai, N., et al. (2012). Comprehensive microRNA Profiling in B-Cells of Human Centenarians by Massively Parallel Sequencing. BMC Genomics 13, 353. doi:10.1186/1471-216413-353

Groenendyk, J., Peng, Z., Dudek, E., Fan, X., Mizianty, M. J., Dufey, E., et al. (2014). Interplay between the Oxidoreductase PDIA6 and microRNA-322 Controls the Response to Disrupted Endoplasmic Reticulum Calcium Homeostasis. Sci. Signal. 7, ra54. doi:10.1126/scisignal.2004983

Guarner-Lans, V., Rubio-Ruiz, M. E., Pérez-Torres, I., and Baños de MacCarthy, G. (2011). Relation of Aging and Sex Hormones to Metabolic Syndrome and Cardiovascular Disease. Exp. Gerontol. 46, 517-523. doi:10.1016/ j.exger.2011.02.007

Hamrick, M. W., Herberg, S., Arounleut, P., He, H.-Z., Shiver, A., Qi, R.-Q., et al. (2010). The Adipokine Leptin Increases Skeletal Muscle Mass and Significantly Alters Skeletal Muscle miRNA Expression Profile in Aged Mice. Biochem. Biophysical Res. Commun. 400, 379-383. doi:10.1016/j.bbrc.2010.08.079

Han, S., Liang, C.-P., Devries-Seimon, T., Ranalletta, M., Welch, C. L., CollinsFletcher, K., et al. (2006). Macrophage Insulin Receptor Deficiency Increases ER Stress-Induced Apoptosis and Necrotic Core Formation in Advanced Atherosclerotic Lesions. Cel Metab. 3, 257-266. doi:10.1016/j.cmet.2006.02.008

He, L., Yuan, J., Xu, Q., Chen, R., Chen, L., and Fang, M. (2016). miRNA-1283 Regulates the PERK/ATF4 Pathway in Vascular Injury by Targeting ATF4. PLoS One 11, e0159171. doi:10.1371/journal.pone.0159171

He, N., Zhang, Y. L., Zhang, Y., Feng, B., Zheng, Z., Wang, D., et al. (2020). Circulating MicroRNAs in Plasma Decrease in Response to Sarcopenia in the Elderly. Front. Genet. 11, 167. doi:10.3389/fgene.2020.00167

Hebert, S. S., Horre, K., Nicolai, L., Papadopoulou, A. S., Mandemakers, W., Silahtaroglu, A. N., et al. (2008). Loss of microRNA Cluster miR-29a/b-1 in Sporadic Alzheimer's Disease Correlates with Increased BACE1/-secretase Expression. Proc. Natl. Acad. Sci. 105, 6415-6420. doi:10.1073/pnas.0710263105

Hooten, N. N., Fitzpatrick, M., Wood, W. H., 3rd, De, S., Ejiogu, N., Zhang, Y., et al. (2013). Age-related Changes in microRNA Levels in Serum. Aging 5, 725-740. doi:10.18632/aging.100603
Hoozemans, J. J. M., Van Haastert, E. S., Eikelenboom, P., De Vos, R. A. I., Rozemuller, J. M., and Scheper, W. (2007). Activation of the Unfolded Protein Response in Parkinson's Disease. Biochem. Biophysical Res. Commun. 354, 707-711. doi:10.1016/j.bbrc.2007.01.043

Hotamisligil, G. S. (2006). Inflammation and Metabolic Disorders. Nature 444, 860-867. doi:10.1038/nature05485

Hou, Y., Dan, X., Babbar, M., Wei, Y., Hasselbalch, S. G., Croteau, D. L., et al. (2019). Ageing as a Risk Factor for Neurodegenerative Disease. Nat. Rev. Neurol. 15, 565-581. doi:10.1038/s41582-019-0244-7

Huang, W. (2017). MicroRNAs: Biomarkers, Diagnostics, and Therapeutics. Methods Mol. Biol. 1617, 57-67. doi:10.1007/978-1-4939-7046-9_4

Huang, Y., Sun, G., Liu, J., Fan, L., Wang, F., Yu, H., et al. (2016). miR-663 Overexpression Induced by Endoplasmic Reticulum Stress Modulates Hepatocellular Carcinoma Cell Apoptosis via Transforming Growth Factor Beta 1. Onco Targets Ther. 9, 1623-1633. doi:10.2147/OTT.S96902

Hussain, S. G., and Ramaiah, K. V. A. (2007). Reduced eIF2 $\alpha$ Phosphorylation and Increased Proapoptotic Proteins in Aging. Biochem. Biophysical Res. Commun. 355, 365-370. doi:10.1016/j.bbrc.2007.01.156

Ito, K., Barnes, P. J., and Rodrigues, F. (2009). A DPOC como uma doença de envelhecimento acelerado. Revista Portuguesa de Pneumologia (English Edition) 15, 743-746. doi:10.1016/S0873-2159(15)30173-2

Jazbutyte, V., Fiedler, J., Kneitz, S., Galuppo, P., Just, A., Holzmann, A., et al. (2013). MicroRNA-22 Increases Senescence and Activates Cardiac Fibroblasts in the Aging Heart. Age 35, 747-762. doi:10.1007/s11357-012-9407-9

Jiang, H.-Y., Wek, S. A., Mcgrath, B. C., Scheuner, D., Kaufman, R. J., Cavener, D. R., et al. (2003). Phosphorylation of the a Subunit of Eukaryotic Initiation Factor 2 Is Required for Activation of NF-Kb in Response to Diverse Cellular Stresses. Mol. Cel Biol 23, 5651-5663. doi:10.1128/MCB.23.16.5651-5663.2003

Jiang, L., Qiao, Y., Wang, Z., Ma, X., Wang, H., and Li, J. (2020). Inhibition of microRNA-103 Attenuates Inflammation and Endoplasmic Reticulum Stress in Atherosclerosis through Disrupting the PTEN-mediated MAPK Signaling. J. Cel Physiol 235, 380-393. doi:10.1002/jcp.28979

Jiang, T., Yu, J.-T., and Tan, L. (2012). Novel Disease-Modifying Therapies for Alzheimer's Disease. J. Alzheimers. Dis. 31, 475-492. doi:10.3233/JAD-2012120640

Jiao, Q., Takeshima, H., Ishikawa, Y., and Minamisawa, S. (2012). Sarcalumenin Plays a Critical Role in Age-Related Cardiac Dysfunction Due to Decreases in SERCA2a Expression and Activity. Cell Calcium 51, 31-39. doi:10.1016/ j.ceca.2011.10.003

Jin, C., Jin, Z., Chen, N.-z., Lu, M., Liu, C.-b., Hu, W.-L., et al. (2016). Activation of IRE1a-XBP1 Pathway Induces Cell Proliferation and Invasion in Colorectal Carcinoma. Biochem. Biophysical Res. Commun. 470, 75-81. doi:10.1016/ j.bbrc.2015.12.119

Kabaria, S., Choi, D. C., Chaudhuri, A. D., Mouradian, M. M., and Junn, E. (2015). Inhibition of miR-34b and miR-34c Enhances $a$-synuclein Expression in Parkinson's Disease. FEBS Lett. 589, 319-325. doi:10.1016/j.febslet.2014.12.014

Kennerdell, J. R., Liu, N., and Bonini, N. M. (2018). MiR-34 Inhibits Polycomb Repressive Complex 2 to Modulate Chaperone Expression and Promote Healthy Brain Aging. Nat. Commun. 9, 4188. doi:10.1038/s41467-01806592-5

Kim, J., Yoon, H., Chung, D.-e., Brown, J. L., Belmonte, K. C., and Kim, J. (2016). miR-186 Is Decreased in Aged Brain and Suppresses BACE1 Expression. J. Neurochem. 137, 436-445. doi:10.1111/jnc.13507

Kim, T., and Croce, C. M. (2021). MicroRNA and ER Stress in Cancer. Semin. Cancer Biol. 75, 3-14. doi:10.1016/j.semcancer.2020.12.025

Koh, H.-J., Toyoda, T., Didesch, M. M., Lee, M.-Y., Sleeman, M. W., Kulkarni, R. N., et al. (2013). Tribbles 3 Mediates Endoplasmic Reticulum Stress-Induced Insulin Resistance in Skeletal Muscle. Nat. Commun. 4, 1871. doi:10.1038/ ncomms 2851

Kumar, S., Vijayan, M., Bhatti, J. S., and Reddy, P. H. (2017). MicroRNAs as Peripheral Biomarkers in Aging and Age-Related Diseases. Prog. Mol. Biol. Transl Sci. 146, 47-94. doi:10.1016/bs.pmbts.2016.12.013

Lee, R. C., Feinbaum, R. L., and Ambros, V. (1993). The C. elegans Heterochronic Gene Lin-4 Encodes Small RNAs with Antisense Complementarity to Lin-14. Cell 75, 843-854. doi:10.1016/0092-8674(93)90529-y

Lemmer, I. L., Willemsen, N., Hilal, N., and Bartelt, A. (2021). A Guide to Understanding Endoplasmic Reticulum Stress in Metabolic Disorders. Mol. Metab. 47, 101169. doi:10.1016/j.molmet.2021.101169 
Li, J., and Holbrook, N. J. (2004). Elevated Gadd153/chop Expression and Enhanced C-Jun N-Terminal Protein Kinase Activation Sensitizes Aged Cells to ER Stress. Exp. Gerontol. 39, 735-744. doi:10.1016/ j.exger.2004.02.008

Li, M., Zhang, S., Qiu, Y., He, Y., Chen, B., Mao, R., et al. (2017). Upregulation of miR-665 Promotes Apoptosis and Colitis in Inflammatory Bowel Disease by Repressing the Endoplasmic Reticulum Stress Components XBP1 and ORMDL3. Cell Death Dis 8, e2699. doi:10.1038/cddis.2017.76

Li, N., Bates, D. J., An, J., Terry, D. A., and Wang, E. (2011a). Up-regulation of Key microRNAs, and Inverse Down-Regulation of Their Predicted Oxidative Phosphorylation Target Genes, during Aging in Mouse Brain. Neurobiol. Aging 32, 944-955. doi:10.1016/j.neurobiolaging.2009.04.020

Li, N., Muthusamy, S., Liang, R., Sarojini, H., and Wang, E. (2011b). Increased Expression of miR-34a and miR-93 in Rat Liver during Aging, and Their Impact on the Expression of Mgst1 and Sirt1. Mech. Ageing Dev. 132, 75-85. doi:10.1016/j.mad.2010.12.004

Li, Q., Liu, T., Yang, S., and Zhang, Z. (2019). Upregulation of miR-34a by Inhibition of IRE $1 \alpha$ Has Protective Effect against $\mathrm{A} \beta$-Induced Injury in $\mathrm{SH}-$ Sy5y Cells by Targeting Caspase-2. Oxidative Med. Cell Longevity 2019, 1-10. doi:10.1155/2019/2140427

Li, X.-X., Zhang, H.-S., Xu, Y.-M., Zhang, R.-J., Chen, Y., Fan, L., et al. (2017). Knockdown of IRE1 $\alpha$ Inhibits Colonic Tumorigenesis through Decreasing $\beta$-catenin and IRE1 $\alpha$ Targeting Suppresses colon Cancer Cells. Oncogene 36, 6738-6746. doi:10.1038/onc.2017.284

Liang, L., Chen, J., Zhan, L., Lu, X., Sun, X., Sui, H., et al. (2015). Endoplasmic Reticulum Stress Impairs Insulin Receptor Signaling in the Brains of Obese Rats. PLoS One 10, e0126384. doi:10.1371/journal.pone.0126384

Lindholm, D., Korhonen, L., Eriksson, O., and Kõks, S. (2017). Recent Insights into the Role of Unfolded Protein Response in ER Stress in Health and Disease. Front. Cel Dev. Biol. 5, 48. doi:10.3389/fcell.2017.00048

Lindholm, D., Wootz, H., and Korhonen, L. (2006). ER Stress and Neurodegenerative Diseases. Cell Death Differ 13, 385-392. doi:10.1038/ sj.cdd. 4401778

Liu, J., Fan, L., Yu, H., Zhang, J., He, Y., Feng, D., et al. (2019). Endoplasmic Reticulum Stress Causes Liver Cancer Cells to Release Exosomal miR-23a$3 p$ and Up-regulate Programmed Death Ligand 1 Expression in Macrophages. Hepatology 70, 241-258. doi:10.1002/hep.30607

Logue, S. E., Mcgrath, E. P., Cleary, P., Greene, S., Mnich, K., Almanza, A., et al. (2018). Inhibition of IRE1 RNase Activity Modulates the Tumor Cell Secretome and Enhances Response to Chemotherapy. Nat. Commun. 9, 3267. doi:10.1038/s41467-018-05763-8

López-Otín, C., Blasco, M. A., Partridge, L., Serrano, M., and Kroemer, G. (2013). The Hallmarks of Aging. Cell 153, 1194-1217. doi:10.1016/ j.cell.2013.05.039

Machida, T., Tomofuji, T., Ekuni, D., Maruyama, T., Yoneda, T., Kawabata, Y., et al. (2015). MicroRNAs in Salivary Exosome as Potential Biomarkers of Aging. Int. J. Mol. Sci. 16, 21294-21309. doi:10.3390/ijms160921294

Maciotta, S., Meregalli, M., and Torrente, Y. (2013). The Involvement of microRNAs in Neurodegenerative Diseases. Front. Cel. Neurosci. 7, 265. doi:10.3389/fncel.2013.00265

Madden, E., Logue, S. E., Healy, S. J., Manie, S., and Samali, A. (2019). The Role of the Unfolded Protein Response in Cancer Progression: From Oncogenesis to Chemoresistance. Biol. Cel 111, 1-17. doi:10.1111/boc.201800050

Maes, O. C., An, J., Sarojini, H., and Wang, E. (2008). Murine microRNAs Implicated in Liver Functions and Aging Process. Mech. Ageing Dev. 129, 534-541. doi:10.1016/j.mad.2008.05.004

Martínez, G., Duran-Aniotz, C., Cabral-Miranda, F., Vivar, J. P., and Hetz, C. (2017). Endoplasmic Reticulum Proteostasis Impairment in Aging. Aging Cell 16, 615-623. doi:10.1111/acel.12599

Maurel, M., and Chevet, E. (2013). Endoplasmic Reticulum Stress Signaling: the microRNA Connection. Am. J. Physiology-Cell Physiol. 304, C1117-C1126. doi:10.1152/ajpcell.00061.2013

Menikdiwela, K. R., Ramalingam, L., Allen, L., Scoggin, S., Kalupahana, N. S., and Moustaid-Moussa, N. (2019). Angiotensin II Increases Endoplasmic Reticulum Stress in Adipose Tissue and Adipocytes. Sci. Rep. 9, 8481. doi:10.1038/s41598019-44834-8

Menikdiwela, K. R., Tôrres Guimarães, J. P., Ramalingam, L., Kalupahana, N. S., Dufour, J. M., Washburn, R. L., et al. (2021). Mechanisms Linking Endoplasmic
Reticulum (ER) Stress and microRNAs to Adipose Tissue Dysfunction in Obesity. Crit. Rev. Biochem. Mol. Biol. 56, 455-481. doi:10.1080/ 10409238.2021.1925219

Mesitov, M. V., Soldatov, R. A., Zaichenko, D. M., Malakho, S. G., Klementyeva, T. S., Sokolovskaya, A. A., et al. (2017). Differential Processing of Small RNAs during Endoplasmic Reticulum Stress. Sci. Rep. 7, 46080. doi:10.1038/srep46080

Naidoo, N., Ferber, M., Master, M., Zhu, Y., and Pack, A. I. (2008). Aging Impairs the Unfolded Protein Response to Sleep Deprivation and Leads to Proapoptotic Signaling. J. Neurosci. 28, 6539-6548. doi:10.1523/JNEUROSCI.5685-07.2008

Naidoo, N., Zhu, J., Zhu, Y., Fenik, P., Lian, J., Galante, R., et al. (2011). Endoplasmic Reticulum Stress in Wake-Active Neurons Progresses with Aging. Aging Cell 10, 640-649. doi:10.1111/j.1474-9726.2011.00699.x

Nolan, K., Mitchem, M. R., Jimenez-Mateos, E. M., Henshall, D. C., Concannon, C. G., and Prehn, J. H. (2014). Increased Expression of MicroRNA-29a in ALS Mice: Functional Analysis of Its Inhibition. J. Mol. Neurosci. 53, 231-241. doi:10.1007/s12031-014-0290-y

Nuss, J. E., Choksi, K. B., Deford, J. H., and Papaconstantinou, J. (2008). Decreased Enzyme Activities of Chaperones PDI and BiP in Aged Mouse Livers. Biochem. Biophysical Res. Commun. 365, 355-361. doi:10.1016/j.bbrc.2007.10.194

O'brien, J., Hayder, H., Zayed, Y., and Peng, C. (2018). Overview of MicroRNA Biogenesis, Mechanisms of Actions, and Circulation. Front. Endocrinol. 9, 402. doi:10.3389/fendo.2018.00402

Ogborn, D. I., Mckay, B. R., Crane, J. D., Parise, G., and Tarnopolsky, M. A. (2014). The Unfolded Protein Response Is Triggered Following a Single, Unaccustomed Resistance-Exercise Bout. Am. J. Physiology-Regulatory, Integr. Comp. Physiol. 307, R664-R669. doi:10.1152/ajpregu.00511.2013

Ong, J., Woldhuis, R. R., Boudewijn, I. M., Van Den Berg, A., Kluiver, J., Kok, K., et al. (2019). Age-related Gene and miRNA Expression Changes in Airways of Healthy Individuals. Sci. Rep. 9, 3765. doi:10.1038/s41598-019-39873-0

Ortega, A., Roselló-Lletí, E., Tarazón, E., Molina-Navarro, M. M., Martínez-Dolz, L., González-Juanatey, J. R., et al. (2014). Endoplasmic Reticulum Stress Induces Different Molecular Structural Alterations in Human Dilated and Ischemic Cardiomyopathy. PLoS One 9, e107635. doi:10.1371/journal.pone.0107635

Ozzan, U., Cao, Q., Yilmaz, E., Lee, A.-H., Iwakoshi, N. N., Ơzdelen, E., et al. (2004). Endoplasmic Reticulum Stress Links Obesity, Insulin Action, and Type 2 Diabetes. Science 306, 457-461. doi:10.1126/science.1103160

Park, S. W., Zhou, Y., Lee, J., Lu, A., Sun, C., Chung, J., et al. (2010). The Regulatory Subunits of PI3K, P $85 \alpha$ and P85 $\beta$, Interact with XBP- 1 and Increase its Nuclear Translocation. Nat. Med. 16, 429-437. doi:10.1038/nm.2099

Paul, P., Chakraborty, A., Sarkar, D., Langthasa, M., Rahman, M., Bari, M., et al. (2018). Interplay between miRNAs and Human Diseases. J. Cel Physiol 233, 2007-2018. doi:10.1002/jcp.25854

Paz Gavilán, M., Vela, J., Castaño, A., Ramos, B., del Río, J. C., Vitorica, J., et al. (2006). Cellular Environment Facilitates Protein Accumulation in Aged Rat hippocampus. Neurobiol. Aging 27, 973-982. doi:10.1016/ j.neurobiolaging.2005.05.010

Perri, E. R., Thomas, C. J., Parakh, S., Spencer, D. M., and Atkin, J. D. (2015). The Unfolded Protein Response and the Role of Protein Disulfide Isomerase in Neurodegeneration. Front. Cel Dev. Biol. 3, 80. doi:10.3389/fcell.2015.00080

Prell, T., Stubendorff, B., Le, T. T., Gaur, N., Tadić, V., Rödiger, A., et al. (2019). Reaction to Endoplasmic Reticulum Stress via ATF6 in Amyotrophic Lateral Sclerosis Deteriorates with Aging. Front. Aging Neurosci. 11, 5. doi:10.3389/fnagi.2019.00005

Rabek, J. P., Boylston III, W. H., 3rd, and Papaconstantinou, J. (2003). Carbonylation of ER Chaperone Proteins in Aged Mouse Liver. Biochem. Biophysical Res. Commun. 305, 566-572. doi:10.1016/s0006-291x(03)00826-x

Rajgor, D., and Hanley, J. (2016). The Ins and Outs of miRNA-Mediated Gene Silencing during Neuronal Synaptic Plasticity. ncRNA 2, 1. doi:10.3390/ ncrna2010001

Ren, J., Bi, Y., Sowers, J. R., Hetz, C., and Zhang, Y. (2021). Endoplasmic Reticulum Stress and Unfolded Protein Response in Cardiovascular Diseases. Nat. Rev. Cardiol. 18, 499-521. doi:10.1038/s41569-021-00511-w

Ren, L., Wang, Q., Chen, Y., Ma, Y., and Wang, D. (2019). Involvement of MicroRNA-133a in the Protective Effect of Hydrogen Sulfide against Ischemia/Reperfusion-Induced Endoplasmic Reticulum Stress and Cardiomyocyte Apoptosis. Pharmacology 103, 1-9. doi:10.1159/ 000492969 
Resende, R., Ferreiro, E., Pereira, C., and Oliveira, C. R. (2008). ER Stress Is Involved in $\mathrm{A} \beta$-induced GSK-3 $\beta$ Activation and Tau Phosphorylation. J. Neurosci. Res. 86, 2091-2099. doi:10.1002/jnr.21648

Rezghi Barez, S., Movahedian Attar, A., and Aghaei, M. (2021). MicroRNA-30c-23p Regulates ER Stress and Induces Apoptosis in Ovarian Cancer Cells Underlying ER Stress. EXCLI J. 20, 922-934. doi:10.17179/excli2020-2970

Ron, D., and Walter, P. (2007). Signal Integration in the Endoplasmic Reticulum Unfolded Protein Response. Nat. Rev. Mol. Cel Biol 8, 519-529. doi:10.1038/ nrm2199

Rupaimoole, R., and Slack, F. J. (2017). MicroRNA Therapeutics: towards a new era for the Management of Cancer and Other Diseases. Nat. Rev. Drug Discov. 16, 203-222. doi:10.1038/nrd.2016.246

Salaroglio, I. C., Panada, E., Moiso, E., Buondonno, I., Provero, P., Rubinstein, M., et al. (2017). PERK Induces Resistance to Cell Death Elicited by Endoplasmic Reticulum Stress and Chemotherapy. Mol. Cancer 16, 91. doi:10.1186/s12943017-0657-0

Salminen, A., Kaarniranta, K., and Kauppinen, A. (2020). ER Stress Activates Immunosuppressive Network: Implications for Aging and Alzheimer's Disease. J. Mol. Med. 98, 633-650. doi:10.1007/s00109-020-01904-z

Santulli, G., Borras, C., Bousquet, J., Calzà, L., Cano, A., Illario, M., et al. (2015). Models for Preclinical Studies in Aging-Related Disorders: One Is Not for All. Transl Med. Unisa 13, 4-12.

Scriven, P., Coulson, S., Haines, R., Balasubramanian, S., Cross, S., and Wyld, L. (2009). Activation and Clinical Significance of the Unfolded Protein Response in Breast Cancer. Br. J. Cancer 101, 1692-1698. doi:10.1038/sj.bjc.6605365

Serna, E., Gambini, J., Borras, C., Abdelaziz, K. M., Belenguer, A., Sanchis, P., et al. (2012). Centenarians, but Not Octogenarians, Up-Regulate the Expression of microRNAs. Sci. Rep. 2, 961. doi:10.1038/srep00961

Shen, D.-F., Qi, H.-P., Ma, C., Chang, M.-X., Zhang, W.-N., and Song, R.-R. (2021). Astaxanthin Suppresses Endoplasmic Reticulum Stress and Protects against Neuron Damage in Parkinson's Disease by Regulating miR-7/SNCA axis. Neurosci. Res. 165, 51-60. doi:10.1016/j.neures.2020.04.003

Shimizu, T., Taguchi, A., Higashijima, Y., Takubo, N., Kanki, Y., Urade, Y., et al. (2020). PERK-mediated Suppression of microRNAs by Sildenafil Improves Mitochondrial Dysfunction in Heart Failure. iScience 23, 101410. doi:10.1016/ j.isci.2020.101410

Shuda, M., Kondoh, N., Imazeki, N., Tanaka, K., Okada, T., Mori, K., et al. (2003). Activation of the ATF6, XBP1 and Grp78 Genes in Human Hepatocellular Carcinoma: a Possible Involvement of the ER Stress Pathway in Hepatocarcinogenesis. J. Hepatol. 38, 605-614. doi:10.1016/s0168-8278(03) 00029-1

Siracusa, J., Koulmann, N., and Banzet, S. (2018). Circulating myomiRs: a New Class of Biomarkers to Monitor Skeletal Muscle in Physiology and Medicine. J. Cachexia, Sarcopenia Muscle 9, 20-27. doi:10.1002/jcsm.12227

Smith-Vikos, T., and Slack, F. J. (2012). MicroRNAs and Their Roles in Aging. J. Cel Sci 125, 7-17. doi:10.1242/jcs.099200

Song, Y., Shen, H., Du, W., and Goldstein, D. R. (2013). Inhibition of X-Box Binding Protein 1 Reduces Tunicamycin-Induced Apoptosis in Aged Murine Macrophages. Aging Cell 12, 794-801. doi:10.1111/acel.12105

Sozen, E., Karademir, B., and Ozer, N. K. (2015). Basic Mechanisms in Endoplasmic Reticulum Stress and Relation to Cardiovascular Diseases. Free Radic. Biol. Med. 78, 30-41. doi:10.1016/j.freeradbiomed.2014.09.031

Sozen, E., and Ozer, N. K. (2017). Impact of High Cholesterol and Endoplasmic Reticulum Stress on Metabolic Diseases: An Updated Mini-Review. Redox Biol. 12, 456-461. doi:10.1016/j.redox.2017.02.025

Sozen, E., Yazgan, B., Tok, O. E., Demirel, T., Ercan, F., Proto, J. D., et al. (2020). Cholesterol Induced Autophagy via IRE1/JNK Pathway Promotes Autophagic Cell Death in Heart Tissue. Metabolism 106, 154205. doi:10.1016/ j.metabol.2020.154205

Spinelli, R., Parrillo, L., Longo, M., Florese, P., Desiderio, A., Zatterale, F., et al. (2020). Molecular Basis of Ageing in Chronic Metabolic Diseases. J. Endocrinol. Invest. 43, 1373-1389. doi:10.1007/s40618-020-01255-z

Sreedhar, R., Giridharan, V. V., Arumugam, S., Karuppagounder, V., Palaniyandi, S. S., Krishnamurthy, P., et al. (2016). Role of MAPK-Mediated Endoplasmic Reticulum Stress Signaling in the Heart during Aging in SenescenceAccelerated Prone Mice. Biofactors 42, 368-375. doi:10.1002/biof.1280

Stacchiotti, A., Grossi, I., García-Gómez, R., Patel, G., Salvi, A., Lavazza, A., et al. (2019). Melatonin Effects on Non-alcoholic Fatty Liver Disease Are Related to
MicroRNA-34a-5p/Sirt1 Axis and Autophagy. Cells 8, 1053. doi:10.3390/ cells8091053

Takeda, N., Kume, S., Tanaka, Y., Morita, Y., Chin-Kanasaki, M., Araki, H., et al. (2013). Altered Unfolded Protein Response Is Implicated in the Age-Related Exacerbation of Proteinuria-Induced Proximal Tubular Cell Damage. Am. J. Pathol. 183, 774-785. doi:10.1016/j.ajpath.2013.05.026

Torres-González, E., Bueno, M., Tanaka, A., Krug, L. T., Cheng, D.-S., Polosukhin, V. V., et al. (2012). Role of Endoplasmic Reticulum Stress in Age-Related Susceptibility to Lung Fibrosis. Am. J. Respir. Cel Mol Biol 46, 748-756. doi:10.1165/rcmb.2011-0224OC

Upton, J.-P., Wang, L., Han, D., Wang, E. S., Huskey, N. E., Lim, L., et al. (2012). IRE1a Cleaves Select microRNAs during ER Stress to Derepress Translation of Proapoptotic Caspase-2. Science 338, 818-822. doi:10.1126/ science.1226191

Uramoto, H., Sugio, K., Oyama, T., Nakata, S., Ono, K., Yoshimastu, T., et al. (2005). Expression of Endoplasmic Reticulum Molecular Chaperone Grp78 in Human Lung Cancer and its Clinical Significance. Lung Cancer 49, 55-62. doi:10.1016/j.lungcan.2004.12.011

Valdes, P., Mercado, G., Vidal, R. L., Molina, C., Parsons, G., Court, F. A., et al. (2014). Control of Dopaminergic Neuron Survival by the Unfolded Protein Response Transcription Factor XBP1. Proc. Natl. Acad. Sci. 111, 6804-6809. doi:10.1073/pnas.1321845111

Vasudevan, S. (2012). Posttranscriptional Upregulation by MicroRNAs. Wiley Interdiscip. Rev. RNA 3, 311-330. doi:10.1002/wrna.121

Vilardo, E., Barbato, C., Ciotti, M., Cogoni, C., and Ruberti, F. (2010). MicroRNA101 Regulates Amyloid Precursor Protein Expression in Hippocampal Neurons. J. Biol. Chem. 285, 18344-18351. doi:10.1074/jbc.M110.112664

Walter, P., and Ron, D. (2011). The Unfolded Protein Response: from Stress Pathway to Homeostatic Regulation. Science 334, 1081-1086. doi:10.1126/ science. 1209038

Wang, G., Yang, Z. Q., and Zhang, K. (2010). Endoplasmic Reticulum Stress Response in Cancer: Molecular Mechanism and Therapeutic Potential. Am. J. Transl Res. 2, 65-74.

Wang, J.-M., Qiu, Y., Yang, Z., Kim, H., Qian, Q., Sun, Q., et al. (2018). IRE1a Prevents Hepatic Steatosis by Processing and Promoting the Degradation of Select microRNAs. Sci. Signal. 11, eaao4617. doi:10.1126/scisignal.aao4617

Wang, J., Chen, J., and Sen, S. (2016). MicroRNA as Biomarkers and Diagnostics. J. Cel. Physiol. 231, 25-30. doi:10.1002/jcp.25056

Wang, W.-X., Rajeev, B. W., Stromberg, A. J., Ren, N., Tang, G., Huang, Q., et al. (2008). The Expression of MicroRNA miR-107 Decreases Early in Alzheimer's Disease and May Accelerate Disease Progression through Regulation of -Site Amyloid Precursor Protein-Cleaving Enzyme 1. J. Neurosci. 28, 1213-1223. doi:10.1523/JNEUROSCI.5065-07.2008

Wang, Y.Liang, Y., and Lu, Q. (2008). MicroRNA Epigenetic Alterations: Predicting Biomarkers and Therapeutic Targets in Human Diseases. Clin. Genet. 74, 307-315. doi:10.1111/j.1399-0004.2008.01075.x

Westrate, L. M., Hoyer, M. J., Nash, M. J., and Voeltz, G. K. (2020). Vesicular and Uncoated Rab1-dependent Cargo Carriers Facilitate ER to Golgi Transport. J. Cel Sci 133, jcs239814. doi:10.1242/jcs.239814

Wu, J., Zhang, R., Torreggiani, M., Ting, A., Xiong, H., Striker, G. E., et al. (2010). Induction of Diabetes in Aged C57B6 Mice Results in Severe Nephropathy. Am. J. Pathol. 176, 2163-2176. doi:10.2353/ajpath.2010.090386

Wu, Q., Ye, X., Xiong, Y., Zhu, H., Miao, J., Zhang, W., et al. (2016). The Protective Role of microRNA-200c in Alzheimer's Disease Pathologies Is Induced by Beta Amyloid-Triggered Endoplasmic Reticulum Stress. Front. Mol. Neurosci. 9, 140. doi:10.3389/fnmol.2016.00140

Xiang, C., Wang, Y., Zhang, H., and Han, F. (2017). The Role of Endoplasmic Reticulum Stress in Neurodegenerative Disease. Apoptosis 22, 1-26. doi:10.1007/s10495-016-1296-4

Xu, H., Tian, Y., Tang, D., Zou, S., Liu, G., Song, J., et al. (2021). An Endoplasmic Reticulum Stress-Micro RNA -26a Feedback Circuit in NAFLD. Hepatology 73, 1327-1345. doi:10.1002/hep.31428

Xu, K., Han, B., Bai, Y., Ma, X.-Y., Ji, Z.-N., Xiong, Y., et al. (2019). MiR-451a Suppressing BAP31 Can Inhibit Proliferation and Increase Apoptosis through Inducing ER Stress in Colorectal Cancer. Cel Death Dis 10, 152. doi:10.1038/ s41419-019-1403-x

Yang, F., Zhang, L., Wang, F., Wang, Y., Huo, X.-s., Yin, Y.-x., et al. (2011). Modulation of the Unfolded Protein Response Is the Core of microRNA-122- 
Involved Sensitivity to Chemotherapy in Hepatocellular Carcinoma. Neoplasia 13, 590-600. doi:10.1593/neo.11422

Yao, Y., Lu, Q., Hu, Z., Yu, Y., Chen, Q., and Wang, Q. K. (2017). A Non-canonical Pathway Regulates ER Stress Signaling and Blocks ER Stress-Induced Apoptosis and Heart Failure. Nat. Commun. 8, 133. doi:10.1038/s41467-017-00171-w

Ye, X., Luo, H., Chen, Y., Wu, Q., Xiong, Y., Zhu, J., et al. (2015). MicroRNAs 99b5p/100-5p Regulated by Endoplasmic Reticulum Stress Are Involved in AbetaInduced Pathologies. Front. Aging Neurosci. 7, 210. doi:10.3389/ fnagi.2015.00210

Yin, L., Sun, Y., Wu, J., Yan, S., Deng, Z., Wang, J., et al. (2015). Discovering Novel microRNAs and Age-Related Nonlinear Changes in Rat Brains Using Deep Sequencing. Neurobiol. Aging 36, 1037-1044. doi:10.1016/ j.neurobiolaging.2014.11.001

Zhang, H., Yang, H., Zhang, C., Jing, Y., Wang, C., Liu, C., et al. (2015). Investigation of microRNA Expression in Human Serum during the Aging Process. J. Gerontol. A. Biol. Sci. Med. Sci. 70, 102-109. doi:10.1093/gerona/ glu145

Zhang, K., Liu, H., Song, Z., Jiang, Y., Kim, H., Samavati, L., et al. (2020). The UPR Transducer IRE1 Promotes Breast Cancer Malignancy by Degrading Tumor Suppressor microRNAs. iScience 23, 101503. doi:10.1016/j.isci.2020.101503

Zhang, X., Azhar, G., and Wei, J. Y. (2012). The Expression of microRNA and microRNA Clusters in the Aging Heart. PLoS One 7, e34688. doi:10.1371/ journal.pone.0034688
Zhang, Z., and Cheng, Y. (2014). miR-16-1 Promotes the Aberranta-Synuclein Accumulation in Parkinson Disease via Targeting Heat Shock Protein 70. Scientific World J. 2014, 1-8. doi:10.1155/2014/938348

Zhou, Y., Lee, J., Reno, C. M., Sun, C., Park, S. W., Chung, J., et al. (2011). Regulation of Glucose Homeostasis through a XBP-1-FoxO1 Interaction. Nat. Med. 17, 356-365. doi:10.1038/nm.2293

Conflict of Interest: The authors declare that the research was conducted in the absence of any commercial or financial relationships that could be construed as a potential conflict of interest.

Publisher's Note: All claims expressed in this article are solely those of the authors and do not necessarily represent those of their affiliated organizations, or those of the publisher, the editors, and the reviewers. Any product that may be evaluated in this article, or claim that may be made by its manufacturer, is not guaranteed or endorsed by the publisher.

Copyright (C) 2022 Demirel-Yalciner, Sozen and Ozer. This is an open-access article distributed under the terms of the Creative Commons Attribution License (CC BY). The use, distribution or reproduction in other forums is permitted, provided the original author(s) and the copyright owner(s) are credited and that the original publication in this journal is cited, in accordance with accepted academic practice. No use, distribution or reproduction is permitted which does not comply with these terms. 